\title{
Fiscalização das Concessões dos Serviços de Energia Elétrica
}

\author{
HERMELINO GatTo \\ (Técnico de administração municipal do Departamento \\ de Assistência aos Municípios, do E. de Minas Gerais)
}

A

teoria das funções municipais defendida por Benedicto Silva, sob o critério da contiguidade, conclui que o grupamento das atividades dos três níveis de govêrno - federal, estadual e municipal - deve ser feito, respectivamente, sob três categorias: atividades de importância mediata; atividades de importância próxima; atividades de importância imediata.

Como atividades de importância imediata, indicamos aquelas que se relacionam com a satisfação das necessidades básicas do indivíduo, ou as que constituem os serviços de primeira necessidade, tais como abastecimento alimentar, água, esgôtn. transporte coletivo, proteção contra incêndios, saneamento, saúde, fôrça, luz e calor, telefone e outros.

E' de todo convinhável que os usuários dos serviços públicos de primeira 11ecessidade estejam em posição de solicitar e receber pronta atenção para os seus desejos, queixas e reclamações, de modo que as correções de falhas verificadas sejam feitas com a maior rapidez, porque sòmente a volta à normalidade restabelece o bem estar do povo - diz êle.

O fornecimento de energia elétrica - de luz, fôrça e calor - é daqueles que se classificam perfeitamente sob esta teoria; entretanto, presentemente, sua concessão e fiscalização se acham centralizadas, em poder da União, sob $\cap$ pressuposto de que, sendo como é, a energia hidráulica, fonte precípua destinada a atender às necessidades do País, pois não possuímos petróleo nem carvão em volume suficiente, deve assim permanecer.

Em abono dessa conclusão, alegou-se que essa fonte essencial de energia se acha sob o contrôle de emprêsas poderosas, constituídas com capitais alienígenas, com capacidade para criarem piramidações e enfeixarem arrecadaçôes e tentáculos ameaģadores ao próprio Estado; às nossas instituições políticas, como aconteceu nos Estados Unidos da América do Norte, se as concessões ficarem à livre iniciativa dos Municípios, isentas de policiamento do Govêrno Federal.

Até razões de ordem interessante à defesa nacional têm sido invocadas nesse sentido.

Estes aspectos, entre outros, ditaram aos constituintes desde 1934, a inclusão da norma constante do art. 151, da Constituição Federal, a fim de que a lei disponha sôbre o regime das emprêsas concessionárias de serviços públicos federais, estaduais e municipais.

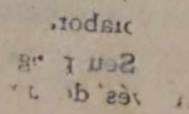


A falta dessa lei regulamentadora gerou a convicção de que se acha em pleno vigor o decreto-lei federal n. ${ }^{\circ} 5.764$, de 19 de agôsto de 1943, daí resultando que tôdas as concessões e a fiscalização da distribuição e comércio de energia elétrica permanecem aferrolhadas no Departamento Nacional de Produção Mineral, do Ministério da Agricultura.

Há julgados confirmando a constitucionalidade dessa centralização, como por exemplo, a decisão do Tribunal Federal de Recursos no caso do município de Joinville, de Santa Catarina.

Juristas de renome, estudiosos đo assunto, já sustentanam, porém, que a lei prevista no art. 151 da Constituição Federal estabelecerá apenas as normas gerais a serem observadas pelas emprêsas concessionárias dos serviços de utilidade pública federais, estaduais e municipais, inclusive quanto ao modo como será feita a fiscalização e a revisão de tarifas dos serviços explorados por concessão, previsão essa, todavia, que não the confere autodeterminação de avocar à União o privilégio das concessões e da fiscalização, pois aos Municípios, por outra norma, é assegurada autonomia especialmente para or ganįzar os serviços locais.

Nem o art. 153, da Constituição Federal contém êsse privilégio, pois, na verdade, a norma nele exarada se restringe às concessões para o aproveitamento das quedas dágua, ou das fontes de energia elétrica.

Daí, a conclusão aprovada no II Congresso Nacional de Municípios que recomenda a revogação do decreto-lei federal n. ${ }^{\circ} 5.764$, de 19 de agôsto de 1943.

Devemos lembrar, nesta oportunidade, que em 1948 já foi apresentado - à Câmara dos Deputados o projeto n. ${ }^{\circ} 1.158$, de autoria do deputado $\mathrm{Pe}$ droso Júnior, com êsse objetivo, projeto êsse arquivado, porém, em face de parecer da Comissão de Justiça, sob duas conclusões: a primeira, declarando que os contratos para os serviços municipais de fornecimento de energia elé. trica são da competência do Município e, a segunda, de que êsses contratos deverão obedecer ao qưe fôr traçado pela lei federal. E mais, que então já se achavam revogadas tôdas as leis anteriores que tiravam ao Município essa competência e, notadamente, o decreto-lei aludido, de n. ${ }^{\circ} 5.764$.

A despeito disso, êle aí está, até hoje, comandando a centralização.

Não nos parece, portanto, que o remédio se encontre na revogação sugerida na conclusão aprovada no II Congresso.

A fiscalização efetiva das emprêsas concessionárias, sob todos os aspectos, não é exercida, por isso que sôbre os ombros do órgão federal sediado na Capital Federal, permanece êsse encargo impossível de ser cumprido, mesmo superficialmente em face das nossas condições peculiares de país territorialmente vasto, com dificuldade de comunicações e variedade de regiões econômicas; longe das necessidades mais triviais da comuna, da conduta dos concessionários em face das mínimas exigências do serviço e do cumprimento das cláusulas contratuais.

Obtidas as concessões, as emprêsas existentes nas regiões mais longínquas do País cumprem-nas ad libitum, porque lá não chega nem pode chegar aquêle órgão da administração federal, ou lá não pode permanecer, quando chega, para atender às queixas que a administração municipal e os consumidores têm diuturnamente a fazer contra os abusos dos concessionários, queixas que afinal 
ficam por fazer, de vez que ninguém irá dirigir-se ao órgão da Capital Federal para solicitar providências quanto a tôda uma infinidade de pequenos serviços negados, ou mal realizados, infrações nas tarifas e outras faltas e deficiências.

A administração municipal, que representa os interêsses dos munícipes, que sente as necessidades coletivas e avalia as deficiências dos serviços, está posta à margem daquela fonte precípua ao progresso da comuna e ao bem estar de seus habitantes. $\mathrm{E}$, mesmo na ocasião em que se elaboram os contratos de concessão, quando é ouvida, isso o é pró forma, pois suas ressalvas são olvidadas.

Impõe-se a necessidade premente da regulamentação das concessões dos serviços de utilidade pública.

Há um sistema preconizado por Bilac Pinto que se nos afigura o mais aconselhável, em face da experiência americana.

A norma constitucional se refere a serviços públicos, enquanto que nós nos referimos a serviços de utilidade pública. $E^{\prime}$ que, evidentemente, o legislador teve o intuito de abrangê-los, salvo conclusão unitária de conceituação. Achamos de bom alvitre apontarmos êste aspecto, pois, segundo Odilon de Andrade, os serviços públicos são os que o Estado impõe e o cidadão sofre, enquanto os de utilidade pública são os que o Estado oferece e o cidadão deles se utiliza, ce quiser. Aqueles visam a utilidade social e êstes a utilidade individual; naqueles a obrigação é legal e o indivíduo é objeto passivo; nestes, a obrigação é contratual e o indivíduo é sujeito ativo; os serviços públicos não têm caráter econômico e não podem ser concedidos, pressupondo-se o monopólio; os serviços de utilidade pública têm caráter econômico e sua exploração pode ser concedida, necessitando declarar-se o monopólio; para atender àqueles há os impostos; êstes são remunerados pelas taxas; na execução dos serviços públicos o agente exerce uma competência - é o funcionário público; na execução dos serviços de utilidade pública, o agente executa um trabalho - é o empregado público. E assim por diante, com exceções que seria fastidioso comentar. Apenas queremos frisar esta conceituação para justificar a diferença que usamos, frente à expressão "serviços públicos" da norma constitucional.

A regulamentação efetiva e imediata das concessões dos serviços de utilidade pública é, portanto, uma das reivindicações mais importantes que devem ser levantadas pelos municípios, de modo que as concessões e a fiscalização, especialmente quanto à distribuição e comércio de energia elétrica, sejam outorgadas pelos órgãos federais, estaduais, seccionais ou municipais próprios.

$\mathrm{E}$ enquanto isso não se verificar, é de necessidade que nova lei temporária dê aos municípios atribuições para fiscalizar a execução dos contratos existentes a fim de se descentralizar em parte, pelo menos, a competência que se encontra algemada nos órgãos federais.

\section{CONCLUSÕES}

\section{I}

Regulamentação efetiva do artigo 151, da Constituição Federal, dentro de curto prazo, sem prejuízo dos interêsses e da autonomia municipais. 


\section{II}

Enquanto não fôr regulamentado o art. 151, da Constituição Federal, a lei dará às administrações municipais, no que fôr possível, concomitantemente com os órgãos próprios da União, competência para fiscalizar as obrigações contratuais relativas às instalações, conservação e execução dos serviços de energia elétrica, cabendo-lhe quota pela execução dessa atribuição.

\section{III}

- A lei disporá que a administração municipal será obrigatòriamente ouvida, ao serem minutados os contratos de concessão, ou renovação, para distribuição e comércio de energia elétrica no respectivo município, cabendo-lhe o direito de recorrer da decisão que desprezar quaisquer das ressalvas por ela oferecidas.

Nota - o recente III Congresso Nacional de Municípios, realizado em São Lourenço, acolheu esta tese e aprovou conclusão determinando o encaminhamento, ao Congresso $\mathrm{Na}$ cional, do seguinte projeto de lei oferecido pelo autor:

\section{PROJETO DE LEI N. ${ }^{\circ}$}

Dá atribuição às administrações municipais para fiscalizarem as concessões para distribuição e comércio de energia elétrica e contém outras providências.

O Congresso Nacional decreta:

Art. $1^{\circ}$ Enquanto não fôr regulamentado o art. 151 , da Constituição, a fiscalização das obrigações adiante especificadas que constarem dos contratos de concessão para distribuição e comércio de energia elétrica, a que se refere o decreto-lei n. ${ }^{\circ} 5.764$, de 19 de agôsto de 1943, passa a ser exercida concomitantemente pela União e pela administração dos municípios interessados.

Art. $2 .^{\circ} \quad$ A fiscalização a que se refere 0 art. $10^{\circ}$ abrange, apenas, as obrigações relativas à manutenção em perfeito estado das instalações gerais do serviço, à observância de tôdas as exigências técnicas constantes dos regulamentos em vigor, à construção e manutenção das instalações necessárias para observações linimétricas e medições de descargas nos cursos dágua utilizados, à ampliação das instalaçóes nas condições determinadas em contrato, ao fornecimento contínuo dentro dos limites de bariações de tensão fixados em regulamento ou instruções, às interrupções não permanentes do fornecimento e à observância das tarifas estipuladas, inclusive das taxas de serviços prestados.

Parágraf́o único. A fiscalização mencionada neste artigo fica restrita à verificação e autuação, segundo as instruções que forem expedidas, cabendo ao órgão competente da União o julgamento e a aplicação da respectiva penalidade, com os recursos previstos em regulamento.

Art. 3. ${ }^{\circ}$ Em tôdas as concessões a serem feitas para distribuição e comércio de energia elétrica, a administração municipal será prèviamente ouvida, sendo-lhe facultado recorrer à autoridade superior, dentro de 90 dias da data da publicação do respectivo têrmo, no caso de não haver sido considerada qualquer das emendas por ela feitas na respectiva minuta.

Art. $4 .^{\circ}$ A limitação estabelecida no art. $20^{\circ}$ não exclui a representação sôbre inobservância de quaisquer das cláusulas contratuais.

Art. 5. ${ }^{\circ}$ A administração municipal perceberá, pela incumbência que the é atribuida nesta lei, a quota que fôr fixada em regulamento.

Art. 6. ${ }^{\circ}$ Fica o Poder Executivo autorizado a regulamentar a presente lei.

Art. $7^{\circ}$ Revogadas as disposições em contrário, entrará esta lei em vigor na data de sua pụblicação. 